\title{
Investigation Report on Influencing Factors of Consumers' Purchasing Behavior of New Energy Vehicles in Changzhou,China
}

\author{
Qing-ming WEI ${ }^{1, a}$, Zi-xuan ZHANG ${ }^{2, b}$, Yu-xin XIA ${ }^{3, c,{ }^{*}}$ \\ ${ }^{1}$ School of Business Administration, HOHAI University, Changzhou Jiangsu, 213022, China \\ ${ }^{2}$ School of Business Administration, HOHAl University, Changzhou Jiangsu, 213022, China \\ ${ }^{3}$ School of Business Administration, HOHAI University, Changzhou Jiangsu, 213022, China \\ aweiqm@hhu.edu.cn, b2248271184@qq.com, cxiayuxin1998learn@163.com \\ *Yu-xin XIA
}

Key words: new energy vehicle consumption behavior decision making factor analysis.

\begin{abstract}
In this paper, the survey survey survey, research analysis and results, research conclusions and suggestions to discuss, a comprehensive analysis of the current consumer behavior to buy new energy vehicles factors, and finally according to the results of statistical analysis of data, for related enterprises to establish a development prospects, in line with consumer demand for products issued The direction of the exhibition. This paper argues that charging time, driving mileage, environmental impact, professional guidance and appearance and interior decoration are important factors affecting consumers' purchase of new energy vehicles, which shows that the convenience, driving ability, appearance and interior decoration and consumption orientation of new energy vehicles are still a major driving force for consumers to choose new energy vehicles.
\end{abstract}

\section{Introduction}

Transportation industry is the second largest carbon emission industry in the world, and its carbon emissions exceed one fifth of the world's total carbon emissions. Therefore, it is the general trend to realize the transformation of vehicle energy and power system under the background of sustainable development. As a new type of green transport, new energy electric vehicles have received more and more attention. The higher it comes. It is estimated that the production capacity of pure electric vehicles and plug-in hybrid vehicles will reach 2 million and the cumulative production and sales will exceed 5 million by 2020. Changing the energy consumption structure and promoting green consumption pattern have become the strategic decision to promote energy conservation, emission reduction and green development.

Consumption is the motive force of production, and green consumption is the source of promoting the development of high quality economy ${ }^{[1]}$. At present, many scholars at home and abroad have studied the factors influencing the consumption of new energy electric vehicles for different groups of people. Tan Juan ${ }^{[2]}$ and others think that the fiscal and tax policies have played a great role in the consumption of new energy electric vehicles; Xu Guohu and Xu Fang ${ }^{[3]}$ through 20 new energy vehicles sales experience. Focus group interviews with salespeople revealed the impact factors; The object of this project is to investigate the factors that influence consumers' purchase of new energy electric vehicles.

\section{Research methods}

\subsection{Research position and respondents}

The survey was conducted in Xinbei District, Tianning District and Wujin District of Changzhou City, as well as in large-scale supermarkets, cinemas and other public places with dense traffic, that is, potential customers to buy new energy vehicles. The subjects of this survey are consumers who have purchased new energy vehicles and consumers who have purchased new energy vehicles in the near future. The overall target is sales promotion objects and all potential consumers of Changzhou new 
energy vehicles. 240 individuals are selected as samples by means of sampling survey. The sample structure is composed of three districts.

\subsection{Data acquisition method}

By using the method of interview and survey, we conduct a questionnaire survey on the interception of consumers who meet the target characteristics in automobile sales places, large supermarkets, cinemas and other densely populated public places. Rate, saving time and manpower cost. This survey is mainly carried out by the way of field survey. We sent out questionnaires in Changzhou Xinbei District, Tianning District and Wujin District. Each District issued 80 questionnaires, a total of 240.

\section{Research and analysis and results}

\subsection{Reliability analysis of questionnaire}

Based on the literature survey, we have collected 33 entries (including duplicate entries). Thirty-three items were merged and classified independently, and the items were added and deleted. Finally, 24 items were determined (see Table 1). This study used SPSS 17.0 to test the overall reliability of 221 questionnaires. The Cronbach's Alpha reliability coefficient was 0.875 , indicating that the questionnaire as a whole has high reliability. The test coefficient for judging sample adequacy was 0.888 , which was greater than 0.5 empirical value. The approximate Chi-square value of Bartlett spherical test was 3983.585, the degree of freedom was 276, and the significance was 0.00 .

Fig. 1. Influence factors and their names.

\begin{tabular}{|c|c|c|c|c|c|}
\hline Influence Factor & Name & Influence Factor & Name & Influence Factor \\
\hline Surrounding people & C1 & Enjoy experiencing new products & C9 & Observe professionals \\
\hline Appearance and interior decoration & C2 & I like to explore the creativity of products & C10 & $\begin{array}{c}\text { Consider the new energy vehicle when } \\
\text { buying the first car }\end{array}$ \\
\hline Driving mileage & C3 & Prefer products with different brands & C11 & $\begin{array}{c}\text { Willing to buy new energy vehicles in } \\
\text { recent years }\end{array}$ & C19 \\
\hline Power supplement mode & C4 & Seen in the media before buying & C12 & $\begin{array}{c}\text { Advertising is attractive when buying new } \\
\text { products }\end{array}$ \\
\hline Convenience of purchase & C5 & Pleasure in using & C13 & Willing to recommend others to use & C21 \\
\hline Charging time & C6 & $\begin{array}{c}\text { Energy saving, emission reduction, } \\
\text { subsidies and other advantages }\end{array}$ & C14 & When you buy second cars, you are willing \\
to choose
\end{tabular}

\subsection{Influencing factors analysis of new energy vehicle purchase decision}

In the survey, consumers who have purchased new energy vehicles in Changzhou, Jiangsu Province, and those who have recently purchased new energy vehicles were asked to score according to the degree of satisfaction or agreement of each decision-making factor. The problem of C1-C13 was measured according to the degree of satisfaction, and the problem of $\mathrm{C} 14-\mathrm{C} 24$ was measured according to the degree of agreement.

In the first factor load, the new energy vehicle charging time, sales price, the use of pleasure coefficient is larger. Among them, the average score of charging time of new energy vehicles is 3.1284, which ranks the first among the factors. It is a decisive factor for consumers to purchase new energy vehicles. Sales price is measured by satisfaction. The average score of sales price was 4.4751 when measured by satisfaction and 3.4574 when measured by agreement. It can be considered as a less important factor in the recent consumer purchase decisions. Therefore, the first factor can be named as "charging time factor".

In the second factor load, the driving mileage of new energy vehicles, the popularity of the surrounding population, celebrity idols have a greater impact coefficient, of which the average driving mileage score is 3.3677 when measuring satisfaction, ranking second in the factors; the average popularity score of the surrounding population is 3.7982 . Celebrity icons scored an average of 3.6433 on a consent scale. Only 9.92 percent of respondents were satisfied with the ability of a new 
energy electric vehicle to run 15 to 20 kilometers on a single charge, otherwise they would choose to buy a traditional car. Therefore, the second factor can be named "continue mileage factor".

In the third factor load, the influence of friends and colleagues, experience a higher degree of innovation of the product coefficient is larger. Friends and colleagues scored an average of 4. 6639 on the consent scale, ranking third among the factors, which was the decision-making factor that consumers valued highly when buying new energy vehicles. Experiencing new products ranked seventh with an average score of 4.1509 on the satisfaction scale; judging from the scores of these two variables, it can be concluded that people in the survey area are vulnerable to the influence of friends and colleagues around when they buy new energy vehicles, because the evaluation and use of others will directly affect the psychological perception of consumers. Value. Bad new energy vehicles may lead to a decline in sales and profits. Therefore, third factors can be named as "environmental impact factor".

In the load of factor 4 , the coefficient of power replenishment mode is bigger, and the average score of satisfaction is 4.3817 , which indicates that the power replenishment mode of new energy vehicles will have some influence on consumers when they make decisions to purchase new energy vehicles, while the existing charging modes of Xinbei District, Wujin District and Tianning District of Changzhou City have obtained the majority. The degree of satisfaction of consumers is relatively high, and related enterprises can regard this as an advantage. In addition, the coefficient of observation professionals at the time of purchase was second only to that of dynamic supplement, and the average score was 4.8453 on the basis of consent, ranking first among the factors of consent. Therefore, in the process of contacting, understanding and choosing to buy new energy electric vehicles, consumers pay more attention to the evaluation and guidance of professionals in the industry. To sum up, fourth factors can be named "professional guidance factor".

Among the loads of factor 5, the coefficient of appearance and interior was the largest, and the average score was 3.4891 when measured by satisfaction. Only $7.99 \%$ of the respondents were satisfied with the appearance and interior of the existing new energy electric vehicles, and $15.43 \%$ were not satisfied with it. This shows that in the emerging phase of new energy vehicles, the appearance and interior is still one of the most important factors to attract consumers to buy. To sum up, fifth factors can be named "appearance and interior factor".

\section{Research conclusions}

When consumers make the decision to buy new energy vehicles, the first influencing factor is the charging time of new energy vehicles, and the shorter the charging time, the more attractive to consumers.

The longer the endurance mileage is, the more obvious the residual power hint is to consumers' attraction. Consumers' main attitude indicates that the current endurance mileage level of new energy vehicles needs to be further improved.

Consumers' decisions to purchase new energy vehicles are vulnerable to the surrounding environment. Family members, friends around the use of feelings and media evaluation will directly affect the psychological perceived value of consumers, consumers make purchase decisions.

As a new product, consumers pay more attention to the evaluation and guidance of professionals in the process of contacting, understanding and choosing to buy new energy electric vehicles. The opinions of professionals are valued and recognized by consumers.

The appearance and interior decoration of new energy vehicles still need improvement. Compared with traditional cars, the appearance and interior of new energy vehicles are difficult to meet consumers' expectations. Therefore, the appearance and interior decoration of new energy vehicles need to be upgraded to better meet the needs of consumers.

\section{Countermeasures and suggestions}

Increase publicity efforts to improve the popularity of related knowledge. The government and the manufacturer should, while perfecting the charging technology of the charging pile, intensify the 
publicity, increase the related activities of the new energy vehicles, provide the citizens with the opportunity to experience, provide convenience for consumers to fully experience the charging service of the new energy vehicles, and promote consumers to understand the new energy vehicles in an all-round way.

Increase the technological $R \& D$ input for upgrading the mileage. Manufacturers and governments need to pay more attention to the mileage of new energy vehicles, continue to develop new energy vehicle battery technology, and increase battery mileage. Emphasis is laid on the development of new graphene-battery technology to improve battery capacity and reduce the amount of electricity required per kilometer of driving, and promote the popularity of new energy vehicles.

Step up publicity efforts to guide and encourage consumers to buy new energy vehicles. The new energy automobile manufacturing industry should cooperate with the media to make use of the group reference effect to increase the sales of new energy automobiles and form a virtuous circle. The media's technological update and product performance promotion of new energy vehicles are conducive to the rapid development of the whole new energy vehicle industry.

Hire professionals as consultants to collect opinions and suggestions. As an emerging product, many consumers are reluctant to make purchase decisions because of their low acceptance. The new energy automobile manufacturing industry can employ professionals to play the role of opinion leaders to enhance the recognition of new energy vehicles to consumers, enhance the psychological perceived value of consumers, and further drive the sales of new energy vehicles.

The appearance and interior decoration of new energy vehicles are diversified. New energy automobile manufacturing enterprises should design appropriate improvement schemes for appearance and interior decoration according to their main consumer groups. If we need to further expand the market share, the new energy automobile enterprises need to design a personalized, meet the needs of the consumer groups to improve the program, in order to eliminate the existing new energy vehicles compared with traditional vehicles, the appearance of a single, convergence defects.

\section{Acknowledgement}

This research was financially supported by the National Undergraduate Innovative Training Progra m (grants 201810294087) and the National Natural Science Foundation of China (grants 71702044)

\section{References}

[1] Xiong Yongqing, He Shuping.Interactive Process Analysis of Target User's Consumption Behavior and Manufacturer's Business Behavior of New Energy Vehicles--Experimental Simulation Based on "Leading" and "Following" Users[J].Science and Technology Management, 2017,38 (11): 61-70.

[2] Tan Juan. Research on consumption of new energy vehicles [J]. Consumption Economy, 2015 (1): $36-40$.

[3] Xu Guohu, Xu Fang. Study on the Influencing Factors of New Energy Vehicle Purchasing Decision [J].China Population, Resources and Environment, 2010, 20 (11): 91-95. 